\title{
Nutritional Status of Children with Intestinal Parasites from a Tropical Area of Bolivia, Emphasis on Zinc and Iron Status
}

\author{
Claudia E. Lazarte ${ }^{1,2 *}$, Andrea Soto ${ }^{2,3}$, Leovegildo Alvarez ${ }^{4}$, Björn Bergenståhl1, \\ Nora Medrano ${ }^{3}$, Yvonne Granfeldt ${ }^{1}$ \\ ${ }^{1}$ Department of Food Technology, Engineering and Nutrition, Lund University, Lund, Sweden \\ ${ }^{2}$ Food and Natural Products Center, San Simón University, Cochabamba, Bolivia \\ ${ }^{3}$ Chagas Disease and Immunoparasitology Laboratory, San Simón University, Cochabamba, Bolivia \\ ${ }^{4}$ Albina Patiño Pediatrics Hospital, Cochabamba, Bolivia \\ Email: ${ }^{*}$ claudia lazarte15@hotmail.com
}

Received 28 February 2015; accepted 16 March 2015; published 23 March 2015

Copyright (C) 2015 by authors and Scientific Research Publishing Inc.

This work is licensed under the Creative Commons Attribution International License (CC BY).

http://creativecommons.org/licenses/by/4.0/

(c) (i) Open Access

\section{Abstract}

Malnutrition and parasitic diseases are within the major issues in rural areas in developing countries. In this study, the nutritional status, dietary intake including mineral absorption inhibitor (phytate), hematological indicators and trace element status (zinc, iron) were evaluated and associated to the presence of intestinal parasites in a group of children from a rural area of Bolivia. The results showed that $96 \%$ of the children had intestinal parasites; 7 types of parasites (Ascaris lumbricoides, Giardia lamblia, Ancylostoma duodenale, Entamoeba histolytica, Entamoeba coli, Trichuris trichiura, Strongyloides stercolaris) were identified. Anthropometric measurements indicated that $37 \%$ of the children were stunted and $17 \%$ were underweight. Iron and zinc intake showed that $34 \%$ and $30 \%$ of children had inadequate intake of these nutrients respectively. Phytate: zinc molar ratios were between 6.5 and 21, and from 6.2 to 15 for phytate: iron, indicating that the absorption of zinc and iron might be compromised by the level of phytate in the diet. The serum zinc was below the lower cut-off in $87 \%$ of the children, indicating zinc deficiency. Moreover, a multiple regression model showed the significant effect of the presence of the parasite Giardia lamblia and phytate intake on the serum zinc levels. Regarding the iron status, $30 \%$ of the children presented with anemia and about $66 \%$ had iron deficiency; a simple linear regression model showed the significant negative effect of the presence of the parasite Ancylostoma duodenale on iron status. In conclusion, the levels of zinc and iron, which were low in this child population, were greatly affected by the presence of intestinal parasites; in addition, the consumption of plant-based diets with high levels of phytate also impaired the zinc absorption.

${ }^{*}$ Corresponding author.

How to cite this paper: Lazarte, C.E., Soto, A., Alvarez, L., Bergenståhl, B., Medrano, N. and Granfeldt, Y. (2015) Nutritional Status of Children with Intestinal Parasites from a Tropical Area of Bolivia, Emphasis on Zinc and Iron Status. Food and Nutrition Sciences, 6, 399-411. http://dx.doi.org/10.4236/fns.2015.64041 


\section{Keywords}

\section{Nutritional Status, Dietary Intake, Zinc, Iron, Deficiency, Phytate, Intestinal Parasites}

\section{Introduction}

Micronutrient deficiencies are a major health problem in developing countries; the conditions can be aggravated by poor diets and infectious diseases which create a complex cycle that is difficult to overcome, especially so in vulnerable populations such as those of pre-schoolchildren because of their higher growth requirements [1]-[3]. Micronutrient deficiencies can be caused by insufficient intake and the presence of absorption inhibitors in the diet, as well as by disease states, such as parasitic infections which are highly prevalent in rural areas in developing countries [4] [5].

Zinc and iron are essential micronutrients for human growth and development, as well as for the maintenance of the immune system, participating in many enzyme and biological processes [6]. Zinc deficiency in particular impairs the immune system, which may lead to an increased susceptibility to infections and an increased severity and incidence of diarrheal, malarial, and respiratory infections among other health problems [4] [7] [8].WHO has estimated the global prevalence of zinc deficiency at 31\%, ranging from 4 to $73 \%$ across different regions in the world [9]. The importance of iron in the metabolism lies in its function as an oxygen binder to hem-containing proteins; the major consequence of iron deficiency is anemia, which produces symptoms of weakness and dizziness. It has also been proved that iron deficiency leads to impairment of the cognitive and psychomotor function, and thus reduced learning or working capacity [10]. According to WHO in developing countries, $48 \%$ of children aged between 4 and 15 years old present with anemia [11].

Zinc and iron deficiencies are also caused by the intake of food with low bioavailability of these essential trace elements, due to the presence of absorption inhibitors such as phytates, polyphenols and oxalates, mainly found in plant-based diets. Phytate is one of the main inhibitors; it has the ability to bind divalent minerals such as $\mathrm{Zn}^{2+}$ and $\mathrm{Fe}^{2+}$, preventing their absorption by the body [12]. Mineral deficiencies can also be provoked by the presence of intestinal parasites, which may negatively impact the host's nutritional status. Intestinal parasitism is caused by unicellular protozoa or multicellular helminthes (worms); it remains an important health problem in developing countries in particular with a higher prevalence of children living in poor rural populations, affecting billions each year. A worldwide intestinal parasite prevalence has been estimated to be higher than $50 \%$ [13]. In Bolivia a prevalence of 20 to $90 \%$ of intestinal pathogenic parasites has been reported in children. There are several mechanisms by which these gastrointestinal parasites impair the nutritional status of the host; they can cause impairment of enzymatic digestion and mucosal absorption leading to endogenous gastrointestinal loss of nutrients, and also they compete for the host's nutrients [14]. Despite the high prevalence of intestinal parasites among child populations, the consequences of specific parasites on trace element status remain being an important topic to be investigated.

In the present pilot study, the nutritional status, including anthropometric indicators, and dietary intake with focus on minerals and mineral absorption inhibitor-phytate, trace elements status (zinc and iron) and hematological indicators were investigated in a group of children from a tropical rural area of Bolivia. The presence of intestinal parasites was also evaluated. Furthermore, regression models were applied to assess the effects of the presence of parasites, and the intake of phytates, on the levels of zinc and iron in serum.

\section{Subjects and Methods}

The pilot study was carried out in a rural area named Ibuelo, located in Chapare, approximately $160 \mathrm{~km}$ east of Cochabamba, Bolivia. Forty-six children from 4 to 13 years old were enrolled in this pilot study. With the help of the local health center we made contact with the school, and the principal of the school randomly (one child after five in the school list) assigned children of different ages. Prior to any enrollment, the parents of the children were informed about the objectives of the study and a statement of consent was signed, and permission was obtained. The exclusion criteria were: children presenting any diseases at the moment of the study, children with diarrhea, and children taking drugs or mineral-vitamin supplements. The study protocol was approved by the 
Ethics Committee of the Albina Patiño Pediatrics Hospital, Cochabamba Bolivia.

\subsection{Anthropometric Measurements}

The children were lightly dressed and without shoes when measurements of height, with a portable stadiometer $\pm 1 \mathrm{~mm}$, and weight using a digital electronic scale $150 \mathrm{~kg} \pm 0.1 \mathrm{~kg}$ (Omron HBF-400) were done, according to standardized procedures [15]. Anthropometric measurements were standardized into age-sex-specific z-scores, which measure the deviation of each individual child's value from the reference child population. Z-scores of height-for-age (HAZ), weight-for-height (WAZ) and body mass index-for-age (BMIAZ) were calculated using the software AnthroPlus (version 10.4; World Health Organization), relative to WHO reference data 2007 [16]. The z-score cut-offs were defined according to WHO classification as follows:

\begin{tabular}{|c|c|}
\hline Stunting & $H A Z<H A Z_{\text {ref(age, sex })}-2 \cdot S D_{\text {HAZ }_{\text {ref(age, sex }}}$ \\
\hline Wasting & $W A Z<W A Z_{\text {ref (age, sex) }}-2 \cdot S D_{\text {HAZ }_{\text {ref(age, sex) }}}$ \\
\hline Underweight & $B M I A Z<B M I A Z_{\text {ref(age, sex) }}-2 \cdot S D_{\text {BMIAZ }_{\text {ref(ase, sex) }}}$ \\
\hline Overweight & $B M I A Z>B M I A Z_{\text {ref (age, sex) }}+1 \cdot S D_{\text {BMIAZ }_{\text {ref(age, sex) }}}$ \\
\hline Obese & $B M I A Z>B M I A Z_{\text {ref(age, sex })}+2 \cdot S D_{\text {BMIAZ }_{\text {ref(aze, sex) }}}$ \\
\hline
\end{tabular}

\subsection{Assessment of Dietary Intake}

The dietary intake of the children was assessed during two consecutive days by the Food Photography 24-hour Recall method (FP24-hR) previously validated and described in detail [17]. Briefly the method consists of a photographic food record, subjects take photographs of all their meals and beverages consumed over a period of time, the method is combined with a 24-hourrecall conducted by nutritionists who visit the subjects after each 24-h period so that they may fill in a questionnaire with detailed information of all of the consumed foods. The method was carried out with small modifications for children under the age of 10; their mothers were responsible for taking the photos before the consumption of the meals, and during the 24-h recall the questions were answered by the mother and child together. Food consumption data were extracted from the questionnaires and the nutrient calculation was done according to the guidelines given in the previously reported method [17]. Moreover, data about the mineral content regarding zinc, iron, calcium and phytate content in the plant-based staple food in this tropical area were included from a previous analytical study [18].

The intake of energy, protein, fat, carbohydrates, fiber, calcium, iron, phosphorus, zinc, cooper, thiamin, riboflavin, niacin, folate, and vitamins A, C, E, B6, and B12 were calculated. These nutrients were selected in order to shed light on possible deficiencies or excesses. The inadequacy of energy intake was evaluated as intakes below two-thirds of the energy expenditure [20], energy expenditure was calculated for each child according their age and weight, with equations from FAO/WHO [19]. Proportion of inadequate intake of nutrients was evaluated by the estimated average requirements (EAR) cut-point method [20] [21], according to the sex and age of each child respectively. Molar ratios Phy:Zn (phytate:zinc) and Phy:Fe (phytate:iron) in the diet of the children are presented as an estimation of the relative bioavailability of iron and zinc in their diet by comparing the ratios with the desirable values. The desirable Phy:Zn is below 15, even though ratios below 5 have also shown a negative effect on zinc absorption [22], the desirable Phy:Fe for an adequate iron absorption is lower than 1 [23].

\subsection{Intestinal Parasites}

The enrolled children were provided with sterile clean leak-proof stool cups for collection. Diagnosis of intestinal parasites was made following standardized procedures of sedimentation and microscopic examination of stool [24], using lugol and formalin-ethyl acetate concentration; the intestinal parasites were studied in 40X magnification field (Biological microscope Model Olympus CX31, OLYMPUS Latin America INC.).

\subsection{Serum Zinc and Iron, Hematological Parameters}

Blood samples $(5 \mathrm{ml}$ ) were drawn from fasting children from the antecubital vein, into trace element-free, hepa- 
rin-container Vacutainer tubes (Becton Dickinson AB, Stockholm, Sweden).The procedures of blood collection and storage follow the guidelines given by IZiNCG [25].

Serum zinc was quantified by flame atomic absorption spectrometry (Model 2280, Perkin Elmer Corporation, Norwalk, CT, USA). Before analysis the samples were diluted 10 times with deionized water [26]. To validate the analysis in serum, the reference material Seronorm ${ }^{\mathrm{TM}}$ (Trace elements serum L-1-2SERO AS, Norway) was used. Serum iron and total iron binding capacity (TIBC) were analyzed by colorimetric procedures with the commercial kits (Fer-color kit, and IUBC/TIBC AA, Weiner Laboratories, Argentina). Percentage of transferrin saturation (\%TS) was calculated as serum iron/TIBC.

Hemoglobin, hematocrit and red blood cells (RBC) were determined by a microhematocrit reader (Microhematocrit system, Model StatSpin CSD2, CritSpin, Iris International Inc., USA). The mean corpuscular volume (MCV) was calculated by dividing the hematocrit by the total number of red blood cells (Hematocrit/RBC) and multiplied by 10 . The mean cell hemoglobin concentration (MCHC) was calculated by dividing the hemoglobin by the hematocrit (hemoglobin/hematocrit).

White blood cells were analyzed in a Neubauer hemocytometer by microscopic examination. Neutrophils, basophils, lymphocytes, eosinophils and monocytes were counted through the morphological evaluation and identification. The count was done with 100X magnification under oil immersion (Biological microscope Model Olympus CX31, OLYMPUS Latin America INC.).

\subsection{Statistical Analysis}

The Statistical Package for Social Sciences (SPSS) version 18.0 (SPSS Inc., IBM corporation 2010, www.spss.com) was used to perform the statistical treatments. The significance level was set up at $P$ values $<$ 0.05. Normality of the data was assessed by Shapiro-Wilk test, and measures of skewness and kurtosis. The majority of the variables do not follow a normal distribution $(P<0.05)$, thus the results are presented as median, minimum and maximum values. Spearman's correlations were computed to study the association between serum zinc and iron with the corresponding micronutrient intakes and with phytate intake.

Simple and multiple linear regression analyses were computed to evaluate the effect of the number and type of parasites found in the children and the effect of phytate and mineral intake, on the levels of zinc and iron in serum. The total group of children was divided into children with specific parasites on the one hand, and the group without these parasites, on the other hand, which was used as a control group, where Man-Whitney U test was used to compare and evaluate differences in nutrient intake, anthropometric indicators, hematological and trace element status between the groups (with and without the parasites). Additionally, one way ANOVAs were used, after dividing the total group of children in subgroups with zero to n-number of different species of parasites found, to examine the effect of polyparasitism on the dietary intake, anthropometric indicators, hematologic and trace element status.

\section{Results}

\subsection{Anthropometric Measurements}

Forty-six children participated in the study: 20 boys and 26 girls; the age range was from 4 to 13 years old. Anthropometric measurements are shown in Table 1, the z-scores HAZ indicated that $37 \%$ of the children were stunted (short for their age), WAZ indicated that $17 \%$ of the children were wasted (thin for their age), BMIAZ indicated that $17 \%$ of children were underweight, $83 \%$ of children were of normal weight and none of them were overweight.

\subsection{Assessment of Dietary Intake}

The dietary evaluation showed that the energy distribution was within the recommended values from WHO [21], $68 \mathrm{E} \%$ was from carbohydrates, $14 \mathrm{E} \%$ was from protein and $19 \mathrm{E} \%$ was from total fat (Table 2).The dietary patterns are mainly based on carbohydrates from cereals (rice, pasta, bread), tubers (potatoes, cassava), and legumes (fava beans, lentils, peanuts), with protein from small portions of meat or eggs and fat from oil and tallow; the vegetables and fruits are present randomly and in small portions. The percentage of children consuming less than two-thirds of their energy expenditure according to their age and sex was $43 \%$, indicating inadequate diets. The analysis of EAR cut-point to evaluate adequate nutrient intakes showed that intakes of protein and carbohydrates 
Table 1. Anthropometric characteristics of children $(n=46)$.

\begin{tabular}{|c|c|c|c|c|}
\hline Anthropometric index & Median & Minimum & Maximum & n (\%) \\
\hline Age, $y$ & 8 & 4 & 13 & \\
\hline Height, $\mathrm{cm}$ & 120 & 94 & 154 & \\
\hline Weight, $\mathrm{kg}$ & 22.5 & 11.3 & 44.0 & \\
\hline $\mathrm{HAZ}^{\mathrm{a}}$ & -1.49 & -3.11 & 0.40 & \\
\hline Stunting (HAZ $\leq 2 \mathrm{SD}$ ) & & & & $17(37)$ \\
\hline Normal & & & & $29(63)$ \\
\hline$W_{A}$ & -1.02 & -3.05 & 0.78 & \\
\hline Wasted (WAZ $\leq 2 \mathrm{SD})$ & & & & $8(17)$ \\
\hline Normal & & & & $38(83)$ \\
\hline BMIAZ $^{\mathrm{c}}$ & -0.21 & -2.08 & 0.93 & \\
\hline Underweight (BMIAZ $\leq 2 \mathrm{SD}$ ) & & & & $8(17)$ \\
\hline Normal & & & & $38(83)$ \\
\hline Overweight (BMIAZ > 2SD) & & & & $0(0)$ \\
\hline
\end{tabular}

${ }^{\mathrm{a} H A Z, ~ z-s c o r e s ~ h e i g h t-f o r ~ a g e ; ~ ' ~}{ }^{\mathrm{b}} \mathrm{WAZ}$, z-scores weight-for age; ${ }^{\mathrm{c} B M I A Z, ~ z-s c o r e s ~ b o d y ~ m a s s ~ i n d e x-f o r-a g e . ~}$

are adequate for all the children. However, fiber intake is inadequate in $100 \%$ of the children, as well as higher levels of inadequacy were found for vitamin E, A and calcium (higher than 90\%), intake of folate and vitamin B12 were inadequate in 65 and 39\% of the children respectively. Regarding zinc and iron intake, the diet of the children showed to be inadequate to meet the requirements in $30 \%$ and $34 \%$ of the children respectively.

Phytate intake was from 0.32 to $1.42 \mathrm{~g} / \mathrm{d}$, with corresponding high molar ratios of Phy:Zn and Phy:Fe likely to impair mineral absorption, 22\% children presented Phy:Zn higher than 15 and 100\% of them had Phy:Fe higher than the desirable value 1 . The high level of phytate was due to some of the main foods in the diet being cereals and legumes, which are known to have high levels of phytate; tubers and roots are the main staple food and also contain phytate.

\subsection{Intestinal Parasites}

Intestinal parasites were found in $96 \%$ of the children. Seven types of parasites were identified; Giardia lamblia $(\mathrm{n}=8$, number of children presenting this parasite), Entamoeba histolytica $(\mathrm{n}=8)$, Entamoeba coli $(\mathrm{n}=5)$, Ancylostoma duodenale $(\mathrm{n}=9)$, Ascaris lumbricoides $(\mathrm{n}=28)$, Trichuris trichiura $(\mathrm{n}=19)$ and Strongyloides stercolaris $(n=2)$. Forty-two percent of the children had one type of parasite, $37 \%$ had two types of parasites, $13 \%$ had up to three types of parasites and $4 \%$ had four types of parasites (Table 3 ).

\subsection{Serum Zinc and Iron, Hematological Parameters}

The levels of zinc and iron in serum are shown in Table 4. The results were compared with reference values compiled by IZiNCG [25] from NHANES III (1988-1994) [5]. Serum zinc was lower in 87\% of the children compared to the reference values $(<65 \mu \mathrm{g} / \mathrm{dl})$ [25], indicating zinc deficiency. Iron status was evaluated by three indicators; serum iron, TIBC and transferrin saturation. According to the results, $84 \%$ of the children present low levels of iron in serum; approximately $66 \%$ of the children were iron deficient and $30 \%$ of the children were with anemia, which is characterized by low serum iron, elevated TIBC and low transferrin saturation. Furthermore, approximately $70 \%$ of the children presented low levels of hemoglobin, hematocrit and red blood cells, which most likely indicates the risk with anemia in these children.

The white blood cell counts were low in $22 \%$ of the children; $63 \%$ of the children presented low levels of lymphocytes, $100 \%$ of them presented high levels of eosinophils, and neutrophils were lower in $33 \%$ of the children; basophils were at the normal level for $98 \%$ of the children and monocytes were lower than the normal level for $100 \%$ of the children (Table 4). 
Table 2. Nutrient intake of children $(\mathrm{n}=46)$.

\begin{tabular}{|c|c|c|c|c|}
\hline Nutrient & Median & Minimum & Maximum & \% children below EAR $^{\mathrm{a}}$ \\
\hline Energy, $M J / d$ & 4.6 & 3.3 & 6.4 & $43^{\mathrm{b}}$ \\
\hline Protein, $g / d(\% \mathrm{E})^{\mathrm{c}}$ & $41(14)$ & $24(10)$ & $54(18)$ & 0 \\
\hline Fat, $g / d(\% \mathrm{E})^{\mathrm{c}}$ & $23(19)$ & $11(11)$ & $46(27)$ & 26 \\
\hline Carbohydrates, g/d (\%E) ${ }^{\mathrm{c}}$ & $185(68)$ & $135(60)$ & $258(77)$ & 0 \\
\hline Fibre, $g / d$ & 12 & 7 & 17 & 100 \\
\hline Calcium, $m g / d$ & 311 & 202 & 558 & 96 \\
\hline Iron, $m g / d$ & 7.9 & 5.5 & 12.5 & 34 \\
\hline Magnesium, $\mathrm{mg} / \mathrm{d}$ & 172.0 & 127.8 & 253.3 & 11 \\
\hline Phosphorus, mg/d & 675 & 374 & 1094 & 40 \\
\hline Zinc, mg/d & 5.6 & 3.6 & 7.5 & 30 \\
\hline Copper, $m g / d$ & 0.78 & 0.53 & 1.08 & 0 \\
\hline Vitamin C, mg/d & 48 & 12 & 159 & 17 \\
\hline Thiamin, $m g / d$ & 0.80 & 0.49 & 1.59 & 4 \\
\hline Riboflavin, mg/d & 0.73 & 0.39 & 1.51 & 26 \\
\hline Niacin, ug/d & 11.1 & 7.1 & 22.3 & 9 \\
\hline Vitamin B-6, mg/d & 1.07 & 0.71 & 2.29 & 0 \\
\hline Folate, $u g / d$ & 172 & 98 & 267 & 65 \\
\hline Vitamin B-12, ug/d & 1.25 & 0.46 & 2.57 & 39 \\
\hline Vitamin A, $\mu g R A E / d$ & 176 & 47 & 341 & 91 \\
\hline Vitamin E, $\alpha$-Tocmg/d & 1.9 & 1.1 & 5.6 & 100 \\
\hline Phytates, g/d & 0.59 & 0.32 & 1.42 & \\
\hline Molar ratio Phy:Zn & 11 & 6.5 & 21 & $(22 \%>15)^{d}$ \\
\hline Molar ratio Phy:Fe & 6.2 & 3.7 & 15 & $(100 \%>1)^{d}$ \\
\hline
\end{tabular}

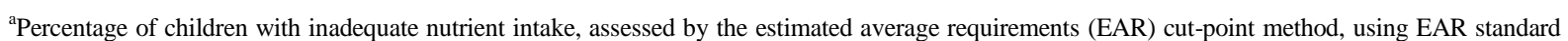
values according to sex and age from WHO [21]; ${ }^{b}$ Percentage of children that meet only two-thirds of their energy expenditure calculated according their age and sex with equations from FAO/WHO [19]; 'Median values of protein, fat and carbohydrates intake and their corresponding percentage of energy intake in parenthesis (\%E); ${ }^{d}$ Percentage of children with molar ratios phytate:mineral, above the suggested molar ratios of Phy:Zn [25] and Phy:Fe [23].

\subsection{Evaluation of Phytate Intake and the Presence of Parasites on the Levels of Serum Zinc and Iron}

Strong negative correlations were found between serum zinc and phytate intake $(r=-0.439, P=0.01)$, as well as with the molar ratio Phy: $\mathrm{Zn}(r=-0.301, P=0.05)$, suggesting that the phytate level in the diet of the children impairs the zinc absorption. The multiple linear regression analysis for evaluating the significance of the effect of phytate and zinc intake on serum zinc, indicated that phytate intake had a significant negative effect $\left(B_{1}=\right.$ $-20.0 \pm 6.9 \mu \mathrm{g} / \mathrm{dl}, r=-0.458, P=0.006)$ on the level of serum zinc; the model shows that serum zinc is decreased by $20.0 \pm 6.9 \mu \mathrm{g} / \mathrm{dl}$ for every additional unit $(\mathrm{g} / \mathrm{d})$ of phytate in the diet. The effect of zinc intake on the serum Zn was not significant $(P=0.824)$.

The simple linear regression analysis for evaluating the effect of each specific parasite on the levels of zincandironin serum showed that the parasites: A. lumbricordes, E. hystolytica, E. coli, T. trichiura and A. stercolaris have no significant effect on the serum levels of these trace elements; neither were any significant differences found when comparing dietary intake, anthropometric indicators and trace element status between children with or without each specific of these parasites.

However, simple linear regression models for G. lamblia and A. duodenale showed a significant effect on the 
Table 3. Frequency and type of parasites in children $(n=46)$.

Intestinal parasites

n (\%)

\section{Number of different parasites ${ }^{a}$}

No parasites

One type of parasites

Two types of parasites

Three types of parasites

Four types of parasites

\section{Type of parasite ${ }^{b}$ \\ Protozoa}

Giardia lamblia

Entamoeba hystolytica

Entamoeba coli

Helminthes

Ascaris lumbricoides

Trichuris trichiura

19

Ancylostoma duodenale

9

Strongyloides stercolaris

2

${ }^{a}$ Frequency of children with none, 1, 2, 3 or 4 parasites; ${ }^{b}$ Number of children with the specific type of parasite.

Table 4. Biochemical, hematological and trace elements status $(n=46)$.

\begin{tabular}{|c|c|c|c|c|c|c|c|}
\hline & Median & Minimum & Maximum & $\begin{array}{c}\text { \%below } \\
\text { reference }\end{array}$ & $\begin{array}{c}\text { \%normal } \\
\text { range }\end{array}$ & $\begin{array}{c}\text { \%above } \\
\text { reference }\end{array}$ & $\begin{array}{c}\text { Reference } \\
\text { values }^{\mathrm{a}}\end{array}$ \\
\hline Hemoglobin, g/dl & 10.5 & 5.7 & 14.6 & 72 & 28 & - & $11.5-15$ \\
\hline Hematocrit, \% & 33.0 & 18.0 & 46.0 & 61 & 11 & 28 & $33-36$ \\
\hline Mean corpuscular volume (MCV), fl & 93.0 & 93.0 & 94.0 & - & - & 100 & $79-80$ \\
\hline Mean cell hemoglobin concentration (MCHC), g/dl & 32 & 32 & 32 & - & 100 & - & $32-36$ \\
\hline Red blood cells, units $\times 10^{6} / \mathrm{mm}^{3}$ & 3.53 & 1.93 & 4.92 & 63 & 26 & 11 & $3.7-4.8$ \\
\hline White blood cells, units $\times 1000 / \mathrm{mm}^{3}$ & 5.3 & 2.4 & 14.4 & 22 & 63 & 15 & $4.0-10.0$ \\
\hline Lymphocytes, \% & 33.0 & 17.0 & 46.0 & 63 & 34 & - & $34-50$ \\
\hline Eosinophils, \% & 23.0 & 4.0 & 38.0 & - & - & 100 & 3 \\
\hline Neutrophils, \% & 43 & 27 & 62 & 33 & 56 & 11 & $42-59$ \\
\hline Basophils, \% & 1 & 1 & 2 & - & 98 & 2 & $0-1$ \\
\hline Monocytes, \% & 1 & 1 & 3 & 100 & - & - & $4-5$ \\
\hline Serum Zn, ug/dl & 55.0 & 40.9 & 81.4 & 87 & 13 & - & $<65$ \\
\hline Serum Fe, $u g / d l(\mathrm{n}=44)^{\mathrm{b}}$ & 32.9 & 11.0 & 95.1 & 84 & 16 & - & $<65$ \\
\hline Serum TIBC ${ }^{\mathrm{c}}, u g / d l(\mathrm{n}=44)^{\mathrm{b}}$ & 319 & 139 & 763 & 2 & 68 & 30 & $240-400$ \\
\hline Serum $\% \mathrm{TS}^{\mathrm{d}}, \%(\mathrm{n}=44)^{\mathrm{b}}$ & 9.7 & 2.2 & 28.5 & 66 & 33 & - & $<16$ \\
\hline
\end{tabular}

${ }^{a}$ Reference values for children, compiled by IZiNCG [25], data derived from NHANES II and WHO [13] [14]. Values for TIBC and \%TS from Cook, 1992 [10]; ${ }^{b}$ Results of iron parameters from 44 samples. Results of 2 samples were discarded because the reported values were extremely low; ${ }^{\circ}$ TIBC, Total iron binding capacity; ${ }^{\mathrm{d}} \% \mathrm{TS}$, Percentage of transferrin saturation. 
levels of serum zinc and iron respectively. The model indicates that the presence of $G$. lamblia had a significant negative effect $(B=-7.4 \pm 3.4 \mu \mathrm{g} / \mathrm{dl}, r=-0.310, P=0.038)$ on the serum zinc of the children. Serum zinc in children with G. lamblia is $7.4 \mu \mathrm{g} / \mathrm{dl}$ lower than serum zinc in children without this parasite. As has previously been shown, phytate intake also had a significant effect on serum zinc; therefore, a multiple linear regression model was applied to evaluate the extent to which the phytate intake and the presence of G. lamblia effect on serum zinc levels; this model showed that the serum zinc is significantly affected by the phytate intake $\left(B_{1}=\right.$ $-15.8 \pm 4.4 \mu \mathrm{g} / \mathrm{dl}, r=-0.482, P=0.001)$ and also by the presence of $G$. lamblia $\left(B_{2}=-6.6 \pm 3.1 \mu \mathrm{g} / \mathrm{dl}, r=\right.$ $-0.310, P=0.035$ ) (Figure 1(a)), indicating that the serum zinc in children is decreased by $15.8 \mu \mathrm{g} / \mathrm{dl}$ for every additional unit of phytate intake. Moreover, the level of zinc in the group of children with G. lamblia is $6.6 \mu \mathrm{g} / \mathrm{dl}$ lower than in the group of children who are free from G. lamblia. There was no significant effect of the presence of $G$. lamblia on the serum iron of the children $(P=0.328)$ (Figure 1(b))

Additionally, the test Man-Whitney $U$ was used to compare the parameters of the dietary intake, anthropometric indicators and trace element status in the group of children infected with G. lamblia $(\mathrm{n}=8)$ and the group of children without this parasite $(\mathrm{n}=38)$. The mean serum zinc level was significantly lower $(P=0.026)$ in the group of children with $G$. lamblia $(49.6 \mu \mathrm{g} / \mathrm{dl})$ compared to the other group $(56.9 \mu \mathrm{g} / \mathrm{dl})$. There were no significant differences in the comparison of zinc intake $(P=0.931)$, phytate intake $(P=0.187)$ or serum iron $(P=$ 0.373 ), neither in the anthropometric and hematological indicators.

The simple linear model to evaluate the presence of the parasite $A$. duodenale, showed a negative significant effect on serum iron $(B=-18.2 \pm 8.4 \mu \mathrm{g} / \mathrm{dl}, r=-0.316, P=0.035)$ (Figure $1(\mathrm{c})$ ). This model indicates that

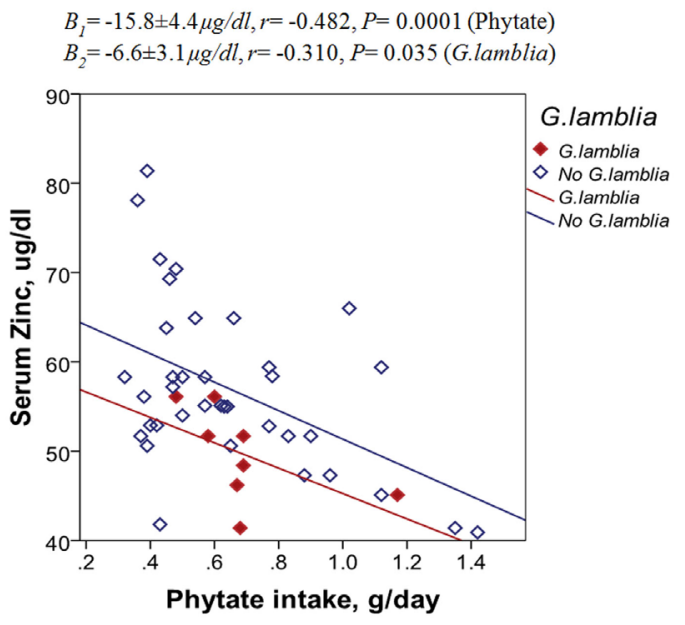

(a)

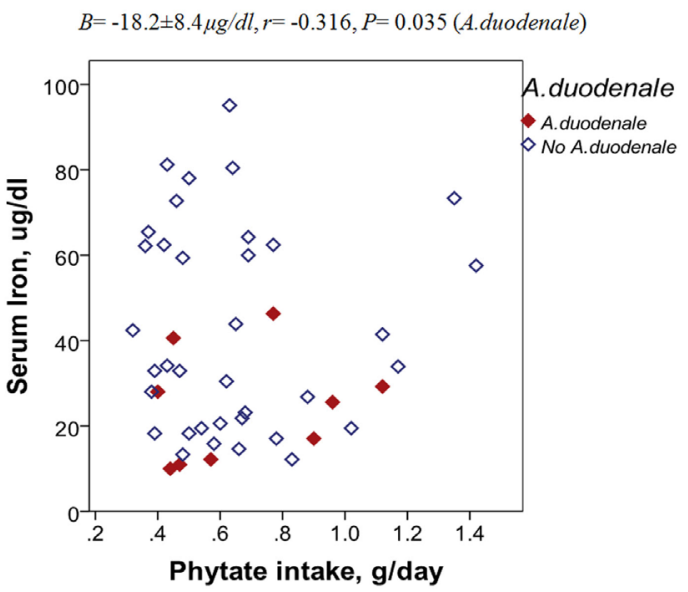

(c)

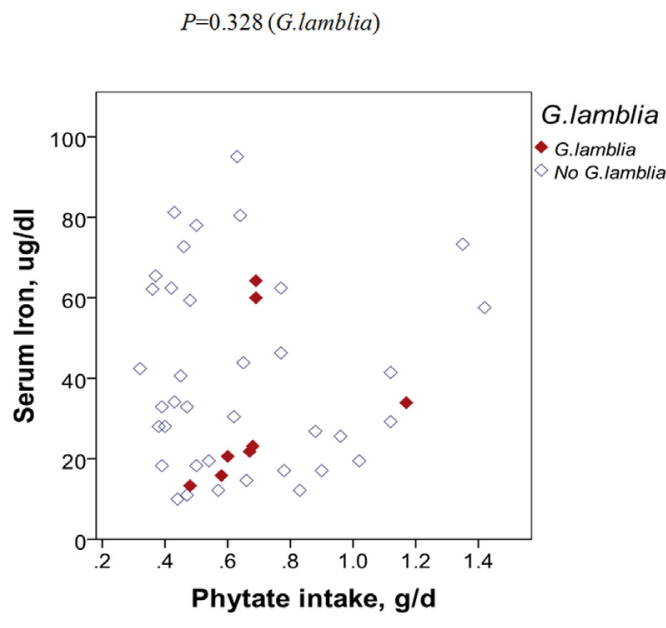

(b)

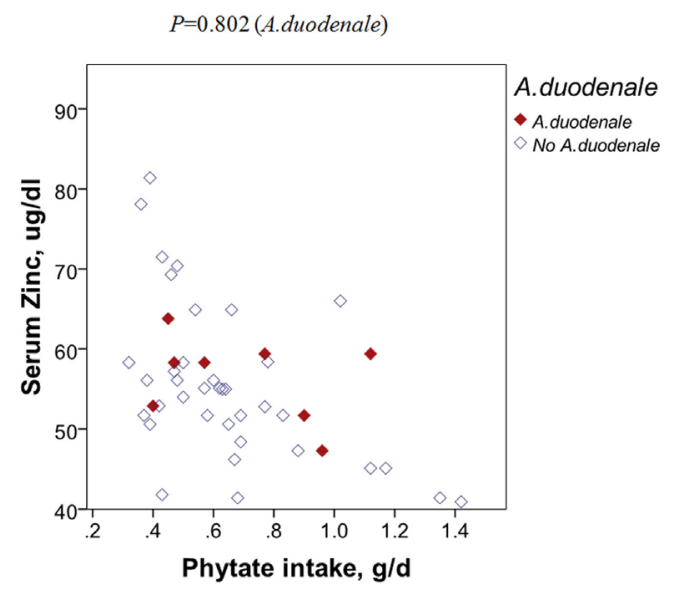

(d)

Figure 1. Effect of the presence of parasites and phytate intake on the serum zinc and iron: (a) G. lamblia on serum zinc; (b) G. lamblia on serum iron; (c) A. duodenale on serum iron and (d) A. duodenale on serum zinc. 
the serum iron in children with A. duodenale is $18.2 \mu \mathrm{g} / \mathrm{dl}$ lower than the level in children who are parasite-free. There was no significant effect on the serum zinc $(P=0.802)$ (Figure $1(d))$. Man-Whitney $U$ test showed that the mean serum iron $(24.5 \mu \mathrm{g} / \mathrm{dl})$ in the group of children with $A$. duodenale $(\mathrm{n}=9)$ was significantly lower $(42.7 \mu \mathrm{g} / \mathrm{dl}, P=0.030)$ than in the group of children without the parasite $(\mathrm{n}=37)$. There were no significant differences in the levels of iron intake $(P=0.923)$, phytate intake $(P=0.771)$, serum zinc $(P=0.372)$ or serum copper $(P=0.825)$. Furthermore, no significant differences were found between the nutrient intakes and anthropometric indicators between these two groups. However, significant differences were found in the level of neutrophils $(P=0.012)$, which was higher in the group of children without the parasite $(46 \%)$ compared to the children with $A$. duodenale $(38 \%)$, and the level of eosinophils was significantly lower $(P=0.008)$ in the group of children without parasites (21\%) compared to the group with A. duodenale (29\%).

One way ANOVA analysis for evaluating the effect of polyparasitism showed no significant differences in the parameters of the dietary intake, anthropometric indicators, hematologic and trace elements in children presenting $0,1,2,3$ or 4 species of different parasites.

\section{Discussion}

The most striking findings of the present study are the very low levels of serum zinc and iron in the children, the absorption of these minerals from their diet showed to be impaired by phytates content in their diet and by the presence of intestinal parasites.

The low levels of serum zinc can be due to several factors: one is a low intake of zinc, as $30 \%$ of the children has inadequate zinc intake. Besides, the main sources of zinc in the studied diet were plant-based foods that provide low bioavailability zinc, due to the presence of phytate, which is mainly found in cereal grains, legumes, seeds and lower levels in tubers [6] [27]; these were the main components of the studied diet, which was in agreement with the findings of previous dietary studies in the same area [17] [28] [29]. In the children's diet, cereal-based foods are staple, for example bread, noodles, rice, wheat; included in staple legumes are fava beans and lentils, and considerable amounts of tubers and roots such as: potatoes, cassava and new cocoyam. The level of phytate in the staple food of the population in this area was analyzed and it has been shown that the high levels of phytate are likely to inhibit the absorption of zinc [18]. The diet of the children in this study showed molar ratios of Phy:Zn between 6.5 and 21.According to the WHO committee, the zinc absorption in this type of diet may be between 15\% (for Phy:Zn > 15) and 30\% of zinc absorption (for Phy:Zn = 5 to 15). It has been reported that ratios between 5 and 15 may have some negative effect on the absorption of zinc, and a Phy:Zn higher than 15 is considered to inhibit zinc absorption [22]. The ratios are similar to those reported in a study of complementary food based on starchy roots and tubers with low mineral bioavailability [28] [30]. Previous studies have also shown that diets in rural areas with high phytate content, following similar dietary patterns to the present diet, impair mineral bioavailability and may lead to zinc deficiencies [28] [31] [33].

Furthermore, the serum zinc level of the children was negatively correlated with the phytate intake and with the molar ratio Phy:Zn. A linear regression model showed that serum zinc is decreased by $20.0 \mu \mathrm{g} / \mathrm{dl}$ for every additional unit (g/d) of phytate in the diet with an inversely significant correlation $(r=-0.458, P=0.006)$. Similar significant inverse correlations (from -0.393 to $-0.652 P=0.05$ ) were reported previously between serum zinc and diets consumed in the same study area [29]. In studies of vegetarian and omnivorous diets, inverse significant associations between Phy:Zn and serum zinc in women with low levels of serum zinc [34] [35] were also reported. It has been reported that high phytate intake decreases intestinal mineral absorptive capacity bearing a significant effect on zinc homeostasis [36].

Intestinal parasitic infections were found to be highly prevalent (96\%) in the studied children in this area; results are consistent with those reported previously, showing high parasitic prevalence among rural tropical areas in Bolivia (72 to 100\%) [37], and in the indigenous population of Beni, high parasitism prevalence from $77 \%$ to $90 \%$ [38] was also found. The 7 different species of parasites identified in the present study are among the most commonly found in South America in general [39], and in Bolivia in particular [37]. The high parasitic prevalence in these areas is associated to the poverty, poor sanitation conditions, inadequate access to safe drinking water, and the fact that animal farming is among the main work activities in the areas surrounding the houses. Furthermore, this is a humid tropical area (300 m above sea level), annual rainfall ranging from 2800 to 5500 $\mathrm{mm}$, average temperature of $26^{\circ} \mathrm{C}$ and relative humidity of $90 \%$, and warm and humid weather was shown to aggravate the prevalence of intestinal parasites, and especially of helminthes [13] [37]. 
Therefore, another important factor for the low zinc levels found, is the presence of intestinal parasites. Several studies have reported the detrimental effect of intestinal parasites on the absorption of various nutrients [40]-[43]. Between the seven types of parasites identified in these children, G. lamblia in particular was found to affect the serum zinc indicated by the linear regression model. Previous studies have reported giardiasis as a risk factor for zinc deficiency in children [40] [42]. One of the explanations for zinc mal-absorption during Giardiasis is that Giardia trophozoites may cause intestinal lesions, greatly impairing intestinal zinc absorption, another reason for the decreased serum zinc levels during parasitic infection is probably the redistribution of zinc from plasma to the liver [44], which was reported during the acute phase response of the host's immune system as a defense mechanism during infections and inflammation episodes. The immune response of the host leads to the activation of the synthesis of metallothionein in liver and other tissues; this appears to alter the hepatic uptake of zinc [45].

The multiple linear regression analysis indicated that both phytate intake and the presence of G. lamblia significantly affect the serum zinc level of the children. Thus, it is important to mention that the high level of phytate impairs the zinc absorption itself, independently of the presence of the parasites, and that this negative effect is exacerbated by the presence of parasites especially G. lamblia. Moreover, due to the intestinal tissue damage caused by G. lamblia, not only zinc absorption, but also other nutrient absorption may be reduced, which may have an effect on weight gain, and is associated with stunting and other health problems in children [46] [47]. In the present study, significant associations between G. lamblia and anthropometric indicators were not found, neither was there an effect due to the other parasites or polyparasitism. Previous studies among rural populations have also failed to find direct associations between the nutritional status measured by anthropometric indicators and intestinal parasites [38] [48]. One of the reasons may be that in these rural tropical areas the high prevalence of intestinal parasites lasts the year-round; thus children would be continuously infected, leading to a chronic low nutritional status in all of them. A bigger sample including non-infected children as a control group must thus be studied in order to evaluate the actual effect of parasites on the nutritional status.

According to the z-scores HAZ, WAZ and BMIAZ, 37\% of the children were stunted, $17 \%$ wasted and $17 \%$ were underweight. One factor contributing to these results, besides the high prevalence of parasites, might be the low energy intake from 3.3 to $6.4 \mathrm{MJ} / \mathrm{d}$, which was shown to be inadequate in $43 \%$ of the children, similar results of low energy intake were previously reported in rural areas of Bolivia for a population between 4 to 18 years old where the energy intakes were from 2.9 to $6.3 \mathrm{MJ} / \mathrm{d}$ [49]. Besides, the high percentage of stunted children may be also associated with the suboptimal serum zinc levels; in this study $87 \%$ of the children present zinc deficiency, and it is reported by previous studies that zinc deficiency is one specific environmental factor that contributes to low HAZ in children, due to several enzymes use different mechanisms that require zinc for nucleic acid metabolism and protein synthesis, thus interfering in the growth process [4] [7].

The evaluation of iron status in the children showed that $84 \%$ of them presented lower values than the reference, $66 \%$ are iron deficient and $30 \%$ of them present anemia. Furthermore, the low levels of hemoglobin and hematocrit are together associated with severe iron deficiency; these levels associated with the high levels of MCV and normal MCHC are an indication of the presence of macrocytic anemia, which is also associated with vitamin B12 and folate deficiency, in the present study $39 \%$ and $65 \%$ of the children have inadequate intake of these nutrients respectively, moreover, the intake of iron was inadequate in $34 \%$ of the children. The obtained results are comparable to previous studies of low serum iron status in children with intestinal parasites [50] [51]. In the present study, a simple linear regression analysis indicated a significant negative effect of the presence of the parasite hookworm A. duodenale on the serum iron. Serum iron in the group of children with A. duodenale was significantly lower $(P=0.030)$ than in the group of children without this parasite. It has been well documented that infections with the nematode parasites such as A. duodenale or $N$. americanus can result in significant iron losses [50] [52], a leading cause of anemia and protein deficiency highly prevalent in tropical areas of developing countries [13]. The mechanism by which the adult hookworms cause low iron levels is based on the attachment of these parasites in the mucosa and sub-mucosa of the small intestine, causing injuries and producing intestinal blood, in addition, these parasites ingest tissue and blood [13] [53].

Regarding the level of lymphocytes, $63 \%$ of the children presented low levels of lymphocytes, indicating the presence of lymphopenia found in several infectious diseases [54]. Moreover, 100\% of them presented high levels of eosinophils, indicating eosinophilia, which is a condition related to parasitic infection, mainly due to the presence of helminthes and hookworm, which may cause tissue damage [55], in the present study, children infected with the hookworm $A$. duodenale showed significantly higher $(P=0.008)$ levels of eosinophils. It seems 
that eosinophils are activated as a defense mechanism against helminthes, eosinophils therefore have the function of destroying helminthes through cellular cytotoxicity [55].

\section{Conclusion}

In conclusion, the low levels of zinc and iron found in children in this study are associated with the low mineral bioavailability and high levels of phytate in the diet, due to the plant-based diet consumed in the area. The low levels of trace elements are also associated with the presence of parasites, particularly G. lamblia and A. duodenale, which have been shown to have a negative effect on the serum zinc and iron respectively. Studies about the relation between nutritional status, trace elements and presence of parasites in children from rural and urban areas are of great importance for developing appropriate nutritional and therapeutic strategies, as well as intervention programs for preventing future adverse effects of untreated intestinal parasite infections.

\section{Acknowledgements}

Financial support from the Swedish International Development Agency (SIDA) is gratefully acknowledged.

\section{References}

[1] Amare, B., Moges, B., Fantahun, B., Tafess, K., Woldeyohannes, D., et al. (2012) Micronutrient Levels and Nutritional Status of School Children Living in Northwest Ethiopia. Nutrition Journal, 11, 108. http://dx.doi.org/10.1186/1475-2891-11-108

[2] Coop, R.L. and Holmes, P.H. (1996) Nutrition and Parasite Interaction. International Journal for Parasitology, 26, 951-962. http://dx.doi.org/10.1016/S0020-7519(96)80070-1

[3] Walravens, P.A., Krebs, N.F. and Hambidge, K.M. (1983) Linear Growth of Low Income Preschool Children Receiving a Zinc Supplement. The American Journal of Clinical Nutrition, 38, 195-201.

[4] Black, R.E. (2003) Zinc Deficiency, Infectious Disease and Mortality in the Developing World. Journal of Nutrition, 133, 1485S-1489S.

[5] Gibson, R. (2005) Principles of Nutritional Assessment. Oxford University Press, New York.

[6] Hotz, C., Lowe, N.M., Araya, M. and Brown, K.H. (2003) Assessment of the Trace Element Status of Individuals and Populations: The Example of Zinc and Copper. The Journal of Nutrition, 133, 1563S-1568S.

[7] Prasad, A.S. (2009) Impact of the Discovery of Human Zinc Deficiency on Health. Journal of the American College of Nutrition, 28, 257-265. http://dx.doi.org/10.1080/07315724.2009.10719780

[8] Shetty, P. (2010) Zinc Deficiency and Infections. In: Nutrition, Immunity and Infection. Cabi Publishing, Wallingford, Oxon, 101-113.

[9] Caulfield, L.E. and Black, R.E. (2004) Zinc Deficiency. In Comparative Quantification of Health Risks. WHO, World Health Organization. Geneva.

[10] Cook, J.D., Baynes, R.D. and Skikne, B.S. (1992) Iron Deficiency and the Measurement of Iron Status. Nutrition Research Reviews, 5, 198-202. http://dx.doi.org/10.1079/NRR19920014

[11] UNICEF/UNU/WHO (2001) Iron Deficiency Anaemia: Assessment, Prevention, and Control. http://www.who.int/nutrition/publications/en/ida_assessment_prevention_control.pdf

[12] Lonnerdal, B. (2002) Phytic Acid-Trace Element (Zn, Cu, Mn) Interactions. International Journal of Food Science and Technology, 37, 749-758. http://dx.doi.org/10.1046/j.1365-2621.2002.00640.x

[13] WHO (2010) Parasitic Diseases. World Health Organization. http://www.who.int/zoonoses/institutions/Parasitic/en/

[14] Solomons, N.W. and Keusch, G.T. (1981) Nutritional Implications of Parasitic Infections. Nutrition Reviews, 39, 149161. http://dx.doi.org/10.1111/j.1753-4887.1981.tb06762.x

[15] WHO (1995) Physical Status: The Use and Interpretation of Anthropometry. Technical Report Series No. 8541995, World Health Organization, Geneva. http://www.who.int/childgrowth/publications/physical_status/en/

[16] WHO (2007) Growth Reference Data for 5 - 19 Years. World Health Organization. http://www.who.int/growthref/en/

[17] Lazarte, C., Encinas, M.E., Alegre, C. and Granfeldt, Y. (2012) Validation of Digital Photographs, as a Tool in 24-h Recall, for the Improvement of Dietary Assessment among Rural Populations in Developing Countries. Nutrition Journal, 11, 61. http://dx.doi.org/10.1186/1475-2891-11-61

[18] Lazarte, C.E., Carlsson, N.-G., Almgren, A., Sandberg, A.-S. and Granfeldt, Y. (2015) Phytate, Zinc, Iron and Calcium Content of Common Bolivian Food, and Implications for Mineral Bioavailability. Journal of Food Composition and 
Analysis, 39, 111-119. http://dx.doi.org/10.1016/j.jfca.2014.11.015

[19] FAO/WHO/UNU, Food and Agricultural Organization, World Health Organization, United Nations University (1985) Energy and Protein Requirements. WHO Technical Report Series 724, World Health Organization, Geneva.

[20] Gibson RS (2005) Principles of Nutritional Assessment. Oxford University Press, New York.

[21] WHO and FAO (2003) Dietary Recommendations in the Report of a Joint WHO/FAO Expert Consultation on Diet, Nutrition and the Prevention of Chronic Diseases. WHO Technical Report Series 916, World Health Organization, Geneva.

[22] WHO (1996) Trace Elements in Human and Health Nutrition. World Health Organization, Geneva. http://whqlibdoc.who.int/publications/1996/9241561734_eng.pdf?ua=1

[23] Hurrell, R.F. (2004) Phytic Acid Degradation as a Means of Improving Iron Absorption. International Journal for Vitamin and Nutrition Research, 74, 445-452. http://dx.doi.org/10.1024/0300-9831.74.6.445

[24] Stenzel, D.J. and Boreham, P.F. (1996) Blastocystis hominis Revisited. Clinical Microbiology Reviews, 9, 563-584.

[25] Hotz, C. and Brown, K.H. (2004) International Zinc Nutrition Consultative Group (IZiNCG) Technical Document No. 1. Assessment of the Risk of Zinc Deficiency in Populations and Options for Its Control. Food and Nutrition Bulletin, 25, S94-S203.

[26] Taylor, A. (1997) Measurement of Zinc in Clinical Samples. Annals of Clinical Biochemistry, 34, 142-150. http://dx.doi.org/10.1177/000456329703400202

[27] Gibson, R.S. and Hotz, C. (2001) Dietary Diversification/Modification Strategies to Enhance Micronutrient Content and Bioavailability of Diets in Developing Countries. British Journal of Nutrition, 85, S159-S166. http://dx.doi.org/10.1079/BJN2001309

[28] Abebe, Y., Bogale, A., Hambidge, K.M., Stoecker, B.J., Bailey, K. and Gibson, R.S. (2007) Phytate, Zinc, Iron and Calcium Content of Selected Raw and Prepared Foods Consumed in Rural Sidama, Southern Ethiopia, and Implications for Bioavailability. Journal of Food Composition and Analysis, 20, 161-168. http://dx.doi.org/10.1016/j.jfca.2006.09.003

[29] Lazarte, C., Alegre, C., Rojas, E. and Granfeldt, Y. (2013) Nutritional Status of Patients with Cutaneous Leishmaniasis from a Tropical Area from Bolivia, and Implications for Zinc Bioavailability. Food and Nutrition Sciences, 4, 49-60. http://dx.doi.org/10.4236/fns.2013.410A009

[30] Mazariegos, M., Hambidge, K.M., Westcott, J.E., Solomons, N.W., Raboy, V., Das, A., et al. (2010) Neither a Zinc Supplement nor Phytate-Reduced Maize nor Their Combination Enhance Growth of 6- to 12-Month-Old Guatemalan Infants. The Journal of Nutrition, 140, 1041-1048. http://dx.doi.org/10.3945/jn.109.115154

[31] Chan, S.S.L., Ferguson, E.L., Bailey, K., Fahmida, U., Harper, T.B. and Gibson, R.S. (2007) The Concentrations of Iron, Calcium, Zinc and Phytate in Cereals and Legumes Habitually Consumed by Infants Living in East Lombok, Indonesia. Journal of Food Composition and Analysis, 20, 609-617. http://dx.doi.org/10.1016/j.jfca.2007.03.003

[32] Gibson, R.S., Bailey, K.B., Gibbs, M. and Ferguson, E.L. (2010) A Review of Phytate, Iron, Zinc, and Calcium Concentrations in Plant-Based Complementary Foods Used in Low-Income Countries and Implications for Bioavailability. Food \& Nutrition Bulletin, 31, 134-146.

[33] Roohani, N., Hurrell, R., Wegmueller, R. and Schulin, R. (2012) Zinc and Phytic Acid in Major Foods Consumed by a Rural and a Suburban Population in Central Iran. Journal of Food Composition and Analysis, 28, 8-15. http://dx.doi.org/10.1016/j.jfca.2012.07.005

[34] Gibson, R.S., Heath, A.L.M., Limbaga, M.L.S., Prosser, N. and Skeaff, C. (2001) Are Changes in Food Consumption Patterns Associated with Lower Biochemical Zinc Status among Women from Dunedin, New Zealand? British Journal of Nutrition, 86, 71-80. http://dx.doi.org/10.1079/BJN2001370

[35] Donovan, U.M. and Gibson, R.S. (1995) Iron and Zinc Status of Young-Women Aged 14 to 19 Years Consuming Vegetarian and Omnivorous Diets. Journal of the American College of Nutrition, 14, 463-472. http://dx.doi.org/10.1080/07315724.1995.10718537

[36] Manary, M.J., Hotz, C., Krebs, N.F., Gibson, R.S., Westcott, J.E., Broadhead, R.L. and Hambidge, K.M. (2002) Zinc Homeostasis in Malawian Children Consuming a High-Phytate, Maize-Based Diet. The American Journal of Clinical Nutrition, 75, 1057-1061.

[37] Mollinedo, S. and Prieto, C. (2006) Enteroparasitología en Bolivia. Ministerio de Salud y Deportes, La Paz. (Document in Spanish).

[38] Tanner, S., Leonard, W.R., McDade, T.W., Reyes-Garcia, V., Godoy, R., et al. (2009) Influence of Helminth Infections on Childhood Nutritional Status in Lowland Bolivia. American Journal of Human Biology, 21, 651-656. http://dx.doi.org/10.1002/ajhb.20944

[39] Hurtado, A.M., Lambourne, C.A., James, P., Hill, K., Cheman, K., et al. (2005) Human Rights, Biomedical, Science, 
and Infectious Diseases among South American Indigenous Groups. Annual Review of Anthropology, 34, 639-665. http://dx.doi.org/10.1146/annurev.anthro.32.061002.093406

[40] Abou-Shady, O., El Raziky, M., Zaki, M. and Mohamed, R. (2011) Impact of Giardia lamblia on Growth, Serum Levels of Zinc, Copper, and Iron in Egyptian Children. Biological Trace Element Research, 140, 1-6. http://dx.doi.org/10.1007/s12011-010-8673-6

[41] Çulha, G. and Sangün, M. (2007) Serum Levels of Zinc, Copper, Iron, Cobalt, Magnesium, and Selenium Elements in Children Diagnosed with Giardia intestinalis and Enterobiosis vermicularis in Hatay, Turkey. Biological Trace Element Research, 118, 21-26. http://dx.doi.org/10.1007/s12011-007-0017-9

[42] Ertan, P., Yereli, K., Kurt, Ö., BalcioĞlu, I.C. and OnaĞ, A. (2002) Serological Levels of Zinc, Copper and Iron Elements among Giardia lamblia Infected Children in Turkey. Pediatrics International, 44, 286-288. http://dx.doi.org/10.1046/j.1442-200X.2002.01550.x

[43] Karakas, Z., Demirel, N., Tarakcioglu, M. and Mete, N. (2001) Serum Zinc and Copper Levels in Southeastern Turkish Children with Giardiasis or Amebiasis. Biological Trace Element Research, 84, 11-18. http://dx.doi.org/10.1385/BTER:84:1-3:011

[44] Singh, A., Smoak, B.L., Patterson, K.Y., Lemay, L.G., Veillon, C., et al. (1991) Biochemnical Indexes of Selected Trace Minerals in Men-Effect of Stress. American Journal of Clinical Nutrition, 53, 126-131.

[45] Schroeder, J.J. and Cousins, R.J. (1990) Interleukin 6 Regulates Metallothionein Gene Expression and Zinc Metabolism in Hepatocyte Monolayer Cultures. Proceedings of the National Academy of Sciences, 87, 3137-3141. http://dx.doi.org/10.1073/pnas.87.8.3137

[46] Çelİksöz, A., Aciöz, M., DeĞerlİ, S., Çinar, Z., Elaldi, N., et al. (2005) Effects of Giardiasis on School Success, Weight and Height Indices of Primary School Children in Turkey. Pediatrics International, 47, 567-571. http://dx.doi.org/10.1111/j.1442-200x.2005.02110.x

[47] Goto, R., Panter-Brick, C., Northrop-Clewes, C.A., Manahdhar, R. and Tuladhar, N.R. (2002) Poor Intestinal Permeability in Mildly Stunted Nepali Children: Associations with Weaning Practices and Giardia lamblia Infection. British Journal of Nutrition, 88, 141-149. http://dx.doi.org/10.1079/BJN2002599

[48] Marini, E., Maldonado-Contreras, A.L., Cabras, S., Hidalgo, G., Buffa, R., et al. (2007) Helicobacter Pylori and Intestinal Parasites Are Not Detrimental to the Nutritional Status of Amerindians. American Journal of Tropical Medicine and Hygiene, 76, 534-540.

[49] Berti, P.R., Jones, A.D., Cruz, Y., Larrea, S., Borja, R., et al. (2010) Assessment and Characterization of the Diet of an Isolated Population in the Bolivian Andes. American Journal of Human Biology, 22, 741-749. http://dx.doi.org/10.1002/ajhb.21075

[50] Stoltzfus, R.J., Chwaya, H.M., Tielsch, J.M., Schulze, K.J., Albonico, M., et al. (1997) Epidemiology of Iron Deficiency Anemia in Zanzibari Schoolchildren: The Importance of Hookworms. The American Journal of Clinical Nutrition, 65, 153-159.

[51] Earley, A., Valman, H.B., Altman, D.G. and Pippard, M.J. (1990) Microcytosis, Iron Deficiency, and Thalassaemia in Preschool Children. Archives of Disease in Childhood, 65, 610-614. http://dx.doi.org/10.1136/adc.65.6.610

[52] Stoltzfus, R.J., Dreyfuss, M.L., Chwaya, H.M. and Albonico, M. (1997) Hookworm Control as a Strategy to Prevent Iron Deficiency. Nutrition Reviews, 55, 223-232. http://dx.doi.org/10.1111/j.1753-4887.1997.tb01609.x

[53] Kalkofen, U.P. (1970) Attachment and Feeding Behavior of Ancylostoma caninum. Zeitschrift Fur Parasitenkunde, 33, 339-354. http://dx.doi.org/10.1007/BF00331470

[54] Feng, C.G., Collazo-Custodio, C.M., Eckhaus, M., Hieny, S., Belkaid, Y., et al. (2004) Mice Deficient in LRG-47 Display Increased Susceptibility to Mycobacterial Infection Associated with the Induction of Lymphopenia. The Journal of Immunology, 172, 1163-1168. http://dx.doi.org/10.4049/jimmunol.172.2.1163

[55] Klion, A.D. and Nutman, T.B. (2004) The Role of Eosinophils in Host Defense against Helminth Parasites. Journal of Allergy and Clinical Immunology, 113, 30-37. http://dx.doi.org/10.1016/j.jaci.2003.10.050 